\title{
A meaningful workplace: Framework, space and context
}

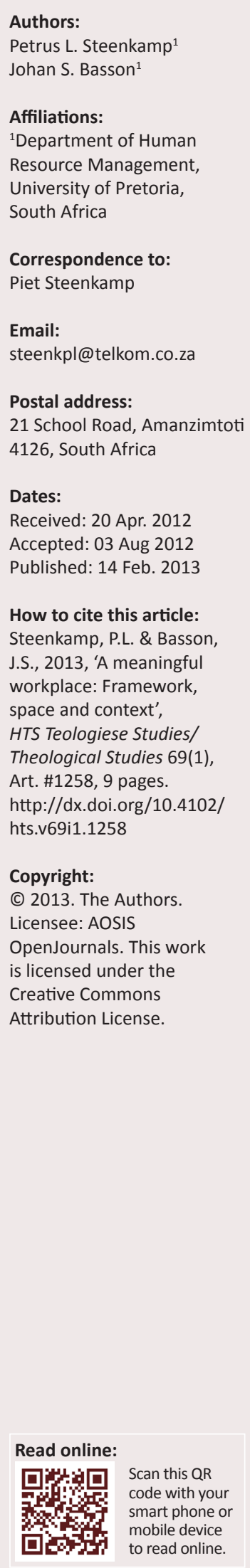

An attempt was made to describe and to eventually implement work space that can be defined as psychologically meaningful and which has increased during the past 5-10 years. Indications are that various researchers on different continents have embarked on a journey to describe the meaningful workplace. Such a workplace is more than a geographical location, it is psychological space; space where the individual employee performs tasks that construe his or her work role, in collaboration with other individuals, within a framework of predetermined time frames, according to certain procedures, based on identified needs and within a formal workflow structure that is normally referred to as the organisation. Within this framework employees become alienated as a result of which the organisation as well as the individual suffer. The organisation experiences a loss of productivity, quality, innovation, et cetera, and the employee a loss of meaning in life and work. Yet, the workplace remains the space where meaning can be gained. It is both the framework and context for meaningfulness at work. Within this framework certain factors and constitutive elements play a facilitating role in experiencing meaningfulness. Various factors including values, and imbedded therein, the Protestant Ethic (PE), (and various other factors, such as for instance spirituality, culture, leadership and management style, etc.), play an important role as facilitating factors towards the experience of meaningfulness at work. Developing a framework and context, on a conceptual level for the positioning of these factors as contributories towards the meaningful workplace, is a first priority. This is what this article is about: to conceptualise the workplace as psychological space, framework and context for understanding the contributory role of PE (and other factors) towards the experience of meaningfulness at work. The positioning of values and the PE as Max Weber understood the concept will be presented in a follow-on article.

\section{Introduction and purpose \\ Background}

This article focuses on the broad framework that was developed during the research endeavour and introduces the construct: 'A Meaningful Workplace'. As such it provides the background to the discussion regarding the Protestant Ethic $(\mathrm{PE})^{1}$ as a contributory towards the construct: 'A Meaningful Workplace', which will be the focus of a second article. PE as a concept, it will be argued, is imbedded and integrated into the construct: 'A Meaningful Workplace', and serves or acts as a contributory towards the creation of a meaningful workplace that is imbued with meaningful work-related experiences.

\section{Purpose}

With this in mind, the imperative imposes itself to, first of all, briefly present the broadest possible framework to the construct: 'A Meaningful Workplace', prior to embarking on a discussion of the $\mathrm{PE}$ as a contributory towards a meaningful workplace.

\section{Problem statement and purpose}

The fundamental problem revolves around the alienation and resultant loss of meaning by individuals in the workplace. As a result there seems to be a movement underfoot to describe the workplace as context for the experience of meaningfulness. However the constituent dimensions are scattered in the literature except for Terez (2000) and Chalofsky (2010). This article addresses the problem of identifying the constituent elements of the meaningful workplace, and presents the construct as context and framework for further investigation (of the different dimensions). Against this backdrop a further article will explore the place and role of Protestant Ethic of the meaningful workplace.

1.The concept 'Protestant Ethic' emanates from the writings of Maximilian Weber [1905] 2002, in an essay with the title: 'The Protestant Ethic and the Spirit of Capitalism' which, according to the research results, substantially contributes towards meaningful work experiences and (by means of inference) serves as a contributory towards the construction of 'A Meaningful Workplace'. 


\section{A meaningful workplace: From theory development to applicability ${ }^{2}$}

The original study identified the dimensions (on a conceptual level) that constitute a meaningful workplace and described a model which can be referred to as 'A Meaningful Workplace' model. The intent was to present a model, based on a theoretical and conceptual understanding that would serve the purpose of a parallel understanding of the behaviour of people in an organisation; to understand the experience of meaning and meaningfulness, whilst at the same time providing an applicable model that could enhance management practice in organisations. Three very specific objectives guided the research process which eventually resulted in the construction of an envisaged model. The objectives are (Steenkamp 2012:70): to conceptualise the constitutive elements of the construct: 'A Meaningful Workplace'; to expand the theoretical base of the construct 'Meaningful Workplace', as presented in literature thereby contributing to the field of organisational behaviour, and to present a practical implementable 'Meaningful Workplace' model based on the research process and as a result of the previous two objectives.

The research program investigated the dynamics that contribute to a meaningful workplace and discovered two macro constitutive dimensions that provide a synergistic perspective towards the construction of a meaningful workplace. The first macro constitutive dimension refers to the meaning of work and encompasses the intrapersonal dimensions that contribute towards the experience of meaningfulness, whilst the second macro constitutive dimension encompasses those dimensions that, from a management perspective, contribute towards the experience of meaningfulness at work. ${ }^{3}$

\section{Research methodology}

The methodological dimension serves as the conduit between the theoretical ideal and the practical ideal. ${ }^{4}$ Following Kotzé (1995:181), who states that qualitative research, represents a better 'fit for the investigation of socio-behavioural phenomena', the research program, focussing on the understanding (Verstehen) of lived experience in the work place was 'inevitably predisposed towards the broad domain of a qualitative approach' (Steenkamp 2012:85). A qualitative approach utilising mixed methods, supplemented by a phenomenological strategy and a constructivist paradigm as the enabling perspectives to pursue the purpose and achieve the objectives of the research program, was followed.

Qualitative researchers function under different epistemological assumptions than do quantitative researchers. The dominant

2.The detailed discussion and reasoning is presented in Steenkamp (2012).

3.The research was conducted with a specific focus on the understanding of meaningfulness as an adjective in combination with 'workplace' thus attempting to understand and describe the meaningful workplace.

4.The discussion here is not a detailed report of all the considerations regarding of either research per se or of qualitative research as such. It is merely intended to provide an understanding of the process that was followed. view in a qualitative approach is the belief that phenomena must be understood in context. The qualitative researcher moves into the dynamic world of the researched phenomenon to experience what it is like to be a part of it (Trochim 2006). It therefore engages (even) adapts, changes and moulds the very phenomena it examines..$^{5}$ The researcher inevitably becomes a co-participant in the research process.

Qualitative researchers also operate under different ontological assumptions about the world and reality. There is no single unitary reality apart from our perceptions. Each individual experiences the world from a particular point of view and therefore every individual experiences or construes a different reality. Research that does not take this into account is viewed as fundamentally violating the fundamental view of the individual. The researcher is a unique individual, and research is based in the individual perception of the researcher. There is thus no point in trying to establish validity in any external or objective sense. All that we can hope to do is to interpret our view of the world as researchers (Steenkamp 2012:111).

Guba and Lincoln (1994) propose four explicit criteria for judging the soundness of qualitative research that better reflect the underlying assumptions that are involved. These include 'credibility, transferability; dependability and confirmability' (Trochim 2006).

\section{Data gathering techniques}

Three data gathering techniques ${ }^{6}$ were employed. The first was to analyse academic and/or scholarly publications. ${ }^{7}$ The second comprised the utilisation of semi-structured Repertory Grid interviews (Kelly 1963; Stewart \& Stewart 1990). The third data gathering method was to analyse organisationally based documents, which included (1) a report of an Information, Communication and Technology (ICT) company (on why employees leave the company when provided the opportunity) and (2) the empirical research conducted by the CRF Institute on the 'best employer' to work for. All the results were aligned to determine certain patterns regarding the construct under discussion. Data were interpreted and purposefully converged through a constructivist approach to eventually create a phenomenological-orientated ${ }^{8}$ framework for understanding work-life experiences, represented as part-theory ${ }^{9}$ towards the enhancement of the emerging conceptual construct: 'A Meaningful Workplace'.

5.Following the dance metaphor (Janesick 1994) qualitative research designs, typically commence with design decisions followed by a phase of execution and eventually it winds down. Design decisions revolve around a question or set of questions that guide the study towards execution. 'Once the researcher has a question, a site, a participant or a number of participants and a reasonable time period .... he or she needs to decide the most appropriate data collection strategies suited to the study (Janesick 1994:211).

6.See Denzin and Lincoln (1994).

7.Formal texts (academic and scholarly publications) represent the results of controlled research and therefore take centre stage.

8.See Bateson (1972); Safranski (1998); Denzin and Lincoln (2000); Gergen and Gergen (2000); Schwandt (2000); Laverty (2003). Smith (2008), and others, a hermeneutical process or approach is applied on a conceptual level. In this process a phenomenological understanding according to Heidegger (see Safranski 1998) is followed. 


\section{Basic assumptions guiding the research towards the construction of the meaningful workplace}

The necessity to state the basic assumptions that guided the research process is self-evident, and follows below.

Assumption 1: Worker alienation and the experience of meaninglessness: In the modern-day world of work, the workplace seems to have become a 'space ${ }^{10}$ where workrelated activities are being performed without a sense of meaning. Employees have to contend with various life roles and the varying demands of these roles. This is especially true of the individual in the work environment. The individual, as an individual or in a group setting, is rigorously managed, based on rational and mechanistic approaches towards work. This has led to a fragmentation of the individual human being - losing perspective of the individual as a whole, integrated being (Chalofsky 2010). In the final analysis, humans suffer from what could be described as an alienation syndrome. Cummings and Manring (1977) describe five dimensions of alienation of employees in the workspace; these include 'work-powerlessness, normlessness, meaninglessness, [negative] self-evaluative involvement, and instrumental work orientation.' Of the five, the significant dimension for our purpose is the concept meaninglessness, as 'the inability to understand the events in which one is engaged' (Cummings \& Manring 1977:169; see also Shepard 1971:14). Meaninglessness at work as a 'type of alienation', together with other types such as powerlessness, normlessness, and estrangement, can be identified as a '... lack of control on the part of the individual over his environment, which produces in him a sense of frustration, powerlessness' (Ashforth 1989:208). Ashforth further postulates a 'three stage process of psychological adjustment.' The first stage is described as 'reactance, the individual attempts to gain the control initially expected or desired'; the second stage is referred to as 'helplessness', during which the individual 'learns that such attempts are largely futile and abandons them' (Ashforth 1989:208).

In the third stage of, 'work alienation', according to Ashforth (1998:208) the individual comes to desire no more than what the status quo affords. Work alienation represents ... a cognitive sense of separation of the individual from work and the workplace that is; a lack of job involvement and organisational identification.

The employee succumbs to an environment where he or she has no control, harbours a dislike and as a result disengages on a psychological level from the workplace. This results in 'emptiness' or a meaningless experience at work. Eventually there develops contempt towards his own self. His existence becomes meaningless (Ashforth 1998:208). ${ }^{11}$

The experience of meaninglessness has major effects such as for instance, a lack of satisfaction, low organisational selfesteem, negative personal self-esteem and poor organisational performance. The individual becomes trapped in a vacuum of

10.The workplace is viewed, primarily, as psychological space and not necessarily as geographical space. Although the geographical dimension cannot be ignored, the research approached the workplace as psychological space.

11.In this connection refer to the discussion by Diamond and Allcorn (2003) personal powerlessness that is governed by systems, processes, structures, procedures and prescriptive regulations. Work becomes a drudgery and a burden which is characterised by the lack of meaningful experiences (Sievers in Chalofsky \& Griffin 2005). ${ }^{12}$ 'Meaning', (Chalofsky \& Griffin 2005:2), 'always played an integral part of work when work was an integral part in the community. ${ }^{\prime 13}$ There is a movement underfoot that demonstrates an interest, research, theorising and discussion regarding the concept 'meaning' in various contexts such as 'meaningful work' the 'meaning of work', 'meaningfulness at work' and 'meaningful workplaces' by authors such as Levering (co-founder of the Great Place to Work Institute 2000), Weisbord (1987), Terez (2000), Chalofsky (2003), May, Gilson and Harter (2004), Mostert (2004), Wiese and Freund (2005), amongst others. The workspace of the postmodern employee, wherein which the individual is deprived of meaning and meaningful experiences has become a target environment where meaning is sought. ${ }^{14}$

Assumption 2: Positive Organisational Science (POS): Following a positive approach, a different posture than a traditional deficit approach is established when viewing the individual in an organisational setting; POS follows a positive approach in respect of the employee in organisational life. As a theoretical framework it moves away from the tendency in psychology to approach phenomena from a deficit assumption.

Since World War 2 (and prior to that event) pathology has been the focus of psychology. This has led to investigations regarding the deficit in human behaviour and attempts at resolving these deficits. With the establishment of positive psychology as a diametrically opposed view to the deficit assumption, the focus falls on three specific domains, that is, positive experiences, positive individual traits and positive institutions (Cameron, Dutton \& Quinn 2003:2).

It is overtly based on the understanding of positive states, (e.g. resilience and meaningfulness) and the dynamics associated with such states (e.g. gratitude, positive connections, community in the workplace, positive workplace culture, etc.). The primary interest is in non-linear positive dynamics,

12.It was the advent of the Industrial era (late 18th century and early 19th century) that finally separated work from community and created an environment or an experiential state in which people do not 'own' their work (Chalofsky \& Griffin 2005).

13.The workplace has displaced the sport club, the social club, the church and in many cases the family as well. In this new environment where people spend the majority of their waking time performing work-related tasks or roles, the post modern employee is deprived of meaning and meaningful experiences. The workplace should also become a target environment where meaning is sought (see Shepard should also become a target environment where meaning is sought (see Shepard [1971]; Cummings \& Manring [1977]; Weisbord [1987]; Terez [2000]; Chalofsky [2003]; Frankl [2004]; May, Gilson \& Harter [2004]; Mostert [2004]; Chalofsky \& Griffin [2005]; Wiese \& Freund [2005]; Chalofsky [2010]). During the 17th century n intimate relationship existed between work and the community. Whatever your occupation or trade, you would socialise with every other member of society. C. 1860 approximately half of the population was self-employed and followe some sort occupational stream, mostly based on inheritance. This situation gradually changed. By the 1900 s approximately $66 \%$ of the population were wage earners and the clock, uniform standards and supervisors came to govern the workplace. Workers subordinated their own experiences to the logic of efficiency and productivity. The advent of enlightenment modernism (advent c. 1890) with its emphasis on rationality made a significant contribution towards this subordination of the individual worker to the logic of efficiency and productivity under the imperative of performance. Although organisations are an integrated part of society, people worked in demarcated areas and were effectively detached from and separated from the larger community or society.

14.Chalofsky (2010:xiii) states that although there are many publications that relate to meaningful work and meaningful workplaces, " none of them offer a substantive account of what constitutes meaningful work and a meaningful workplace, so that individuals can be educated as to what goes into finding or creating fulfilling work, individuals can be educated as to what goes into finding or creating fulfilling work,
and mangers and consultants can understand what it takes to create and sustain a meaningful workplace.' 
or what can also be called positive spirals (Cameron et al. 2003). It studies (and as a consequence builds appropriate theory about) positive phenomena within organisational space. The research towards constructing the meaningful workplace has its origins in the basic ontological assumption of positive organisational science.

Positioning of the research: Organisational Behaviour: The study is positioned within the field of organisational behaviour, an interdependent field of study within the management sciences, that serves itself from subject matter of psychology, sociology, anthropology, management theory, et cetera.

McFillen (1985) identifies the lack of a macro context within which the study of organisational behaviour is studied, as problematic. Macro context in this sense refers to the organisation as context. A superficial glance at textbooks on organisational behaviour (OB) supports this (lack of context) and indicates a measure of fossilisation and a fairly standardised set of topics. These standardised topics perpetuate the fragmentation of the individual in an organisational setting thereby exacerbating alienation and meaninglessness.

Casey (2002) argues convincingly that organisational behaviour has been trapped in a managerialist and structuralfunctionalism based on instrumental-rationalism. As a result the individual, has become a unit of analysis driven by a '... micro-psychologism of the organization behaviourists' (Casey 2002:83) which has become systematically accommodated in the quest for understanding human behaviour at work. The individual in the organisation has as a result become subject to and forced into a culture of managerialism which is solely influenced by a paradigm of achievement and performance imperatives. The sense of self is construed and acknowledged only through performance and only where such an individual eventually becomes a marker of distinction does that individual become self-actualised (Hancock \& Tyler in Rhodes 2003).

The individual has become the object of formal management theory. To aggravate this situation, Industrial/Organisational (I/O) psychology has developed organisational and behavioural theories based on behaviourist thinking and a humanistic paradigm, in order to understand concepts such as motivation, leadership, organisational structures, and development (Robbins 1998). This creates the impression that $\mathrm{OB}$ is only conscious, mechanistic, predictable, uncomplicated and easy to understand.

The last decade has seen a change of attitudes and of people's attitudes toward work and social life that necessitates a new or perhaps different understanding of the world we live in and in which we work:

Individual rationality is replaced by communal negotiating processes; the importance of social processes in the observed enterprise; the socio-practical function of language and the significance of pluralistic cultural investments in the conceptions of true and good. (Gergen \& Thatchenkery 2004:239)

This change of approach has its origins in postmodernism (Miller 1976; Gephart 1996; Cilliers \& Koortzen 2000; Engholm
2001). ${ }^{15}$ According to Engholm (2001): 'Postmodernism developed out of a belief that the world is not accurately described and interpreted by the modernist paradigm.' ${ }^{16}$ Postmodernism calls into question the assumption on which modernism bases its recounting of the truth and reality, and promotes alternative ways to understand the phenomena it is faced with and therefore favours a constructivist type perspective of research to understand reality. It recognises potentialities, a statement that is concomitant with the underlying epistemological approach of positive organisational scholarship. Postmodernism uses a methodological strategy that aims at understanding conditions of possibility (or potentialities), rather than describing cause-effect relationships in organisations (Gephart 1996). Individuals who search for meaning in their daily life and organisational settings, become achievers by choice, based on the meaningfulness of their actions and behaviour, by achieving latent potential. A postmodern and psychodynamic orientation believes that statistical analysis tells very little that is useful about people working in the system. ${ }^{17}$ It also rejects the notion of a grand theory of organisation (Miller 1976).

15.The reasoning regarding organisational behaviour as the field of study and the problems associated with the initial research process can be followed in McFillen (1985), the lack of a macro context within which the study of organisational behaviour is conducted; Casey (2002:83), the entrapment of organisational behaviou in a 'managerialist and structural-functionalism based on instrumental-rationalism' (Chalofsky \& Griffin 2005); hierarchies separate management from workers whilst internal competition to progress, position employees against each other as adversaries. The individual has become the object of formal management theory in organisational life as well as in everyday life, with no or very little room for the intra- and interpersonal construction of realty as a human being at work, at home, intra- and interpersonal construction of realty as a human
on the sports field or in the social contact with others.

16.Further, according to Boje, Gephart and Thatchenkery in Engholm (2001): 'It criticises the modernist's view [...] that there is a universal truth, and that this truth can be discovered by scientific methods and applied in all situations. It criticises modern assumptions about reason and rationality, about normality and deviance and about the best ways of dealing with practical issues of life and society.' The observation that existing conceptions of social life and organisational life seem deficient and inappropriate, if not simply wrong, could be identified as the trigger mechanism for postmodernist thought and method, with a heavier emphasis on qualitative research methodology.

17.Industrial and organisational management gradually evolved towards a more systematic and structured approach. The proliferation of similar industries led owners of industry to focus on cost reduction as a result the so-called traditional or scientific management model evolved. The style of management was authoritarian and ignored the notion of work ethic. Scientific Management assumed that workers were lazy and had to be coerced toward productive endeavours in the workplace. It was assumed that employees neither desired nor were they capable workplace. It was assumed that employees neither desired nor were they capable autonomous work. Scientific Management as a concept imported concepts such autonomous work. Scientific Management as a concept imported concepts such
as specialisation and the division of jobs, breaking these down into the simplest of
tasks, based on the claim that in this way this way production would increase which in turn would lead to monetary gain for the enterprise, and which would then also improve the remuneration of workers. It was then assumed that monetary gain was the only motivational factor towards higher productivity and product output. Daft and Steers (1990) however indicate that other factors (than remuneration) played an important role in the work motivation of workers. After World War I the behaviourist school of thought started replacing scientific management (Jagg 1988) and presented a new set of theoretical considerations for facilitating the and managing employees. The counter-argument, that is, that workers were not and managing employees. The counter-argument, that is, that workers were not intrinsically lazy was proposed together with the perspective that human being were adaptive. This also applied in the workplace. The fallure to challenge (individualy or collectively) would result in procastination or lazy. The opposite was also postulated as true. The response to the new theories of management and organisational behaviour created a trend towards making jobs more fulfilling. In spite of all the efforts (facilitating positive relationships, efforts to make people feel useful and important in the work environment, company newsletters, awards and recognition) the adversity between shop floor and management office continued. The 1950s followed with the drive to enrich jobs, and created a base for fundamental change in these relationships. It was the work of Herzberg, Mausner and Snyderman (1969) who proposed the need to achieve, the need for recognition, the need for responsibility and the need for personal growth that provided the inspiration to perform better. Remuneration, policies to regulate behaviour, management and supervisory style and relationships with fellow workers seemed to inhibit performance if not adequately provided for, but on the other hand, did not really improve motivation not really improve motivation when present. A more radical break with Scientific Management was introduced with the concept of participatory management. Jagg (1988:446) defines participatory management as 'a cooperative process in which management and workers work together to accomplish a common goal. Yet in spite of these movements and perspectives, employees remain alienated and the workplace a meaningless space, where the performance of work related tasks is still without the experience of meaning. 


\section{The meaningful workplace: A holistic conceptual perspective}

What follows is an extremely condensed discussion of the meaningful workplace.

Work occupies a central role in the life of individuals and society, and the outcomes are considered to be a central aspect of life, as it seems to be an important catalyst for the formation of self-esteem, identification, and self-image whilst at the same time being a necessity for fulfilling basic needs (MOW International Research Team 1987 in Sharabi \& Harpaz 2007).

Figure 1 provides a framework for the discussion of a meaningful workplace (as a construct). As has been stated above, two macro constitutive dimensions each with their respective constitutive factors and elements can be synergised towards the conceptual construction of a meaningful workplace. The first macro constitutive dimension is referred to as the 'meaning of work' or meaningful work, which innately refers to the activity or activities which are normally referred to as work activities. The concept meaningful qualifies the experience of employees whilst performing work activities. The second macro constitutive dimension is described as 'meaningfulness at work', indicating meaningful experiences in what can be referred to as the workspace.

In spite of the indications that the 'meaning of work differs from person to person, and from culture to culture' (Nelson \& Quick 2000:466) and that it is important to understand and appreciate differences among individuals and between cultures in this regard, it does however not imply a lack of commonality, or shared meaning across work environments, across cultures, and more specifically, within organisational contexts.

\section{Meaning of work as a macro constitutive dimension of the construct: 'A Meaningful Workplace' 18}

The first macro constitutive dimension towards a meaningful workplace is referred to as meaningful work or alternatively, the meaning of work.

The meaning of work or in the meaningful work model Chalofsky (2010) encompasses various factors that, in conjunction with each other, can be construed as those factors and elements that facilitate the experience of meaningfulness when performing work. These dimensions represent not only a meaningful work model but by way of implication also refer to the whole, integrated human being who performs work in a certain workspace. The following dimensions constitute the meaning of work perspective or model (the distinguishable factors and their constitutive dimensions will be identified without embarking on a detailed discussion):

18.Work is a purposeful activity. The world, in which different generations live was and is created through the purposeful activity that is called work, based on collaborative efforts to enhance our world. Once the purposeful and collaborative efforts were or are initiated, the momentum carries on after the passing of that generation. A next generation expands and builds on established foundations thus creating an ever-evolving world order through the interaction of a myriad of working activities that are continuously being strung together. Humans transform the world according to their requirements. Yet, the affluence has exerted its cos in terms of '... distant impersonal and detached social relations that characterize many contemporary organizations' (Collinson 1992:2).

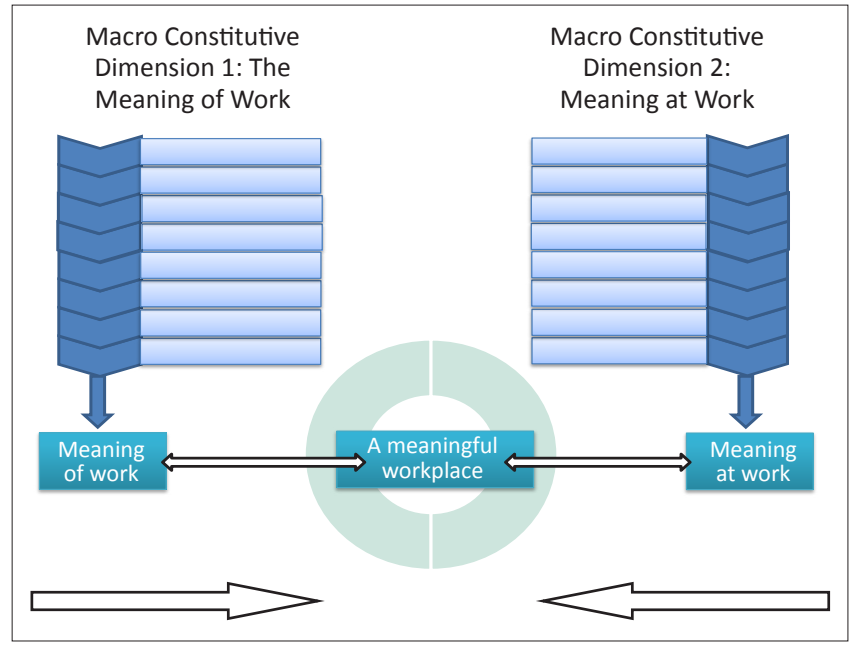

Source: Steenkamp, P.L., 2012, 'A meaningful workplace: From theory development to applicability', PhD thesis, Department of Economic and Management Science, University of Pretoria

FIGURE 1: The macro constitutive dimensions of a meaningful workplace.

Moral philosophy on meaningful work: The experience of meaningfulness while performing work, according to Immanuel Kant (1724-1804) (Bowie 1998; see also Steenkamp 2012:177-187) is represented by the following dimensions that emanate from a moral philosophical perspective. Meaningful work is:

- work that is freely entered into

- work that pays a sufficient wage

- work wherein which the employee can develop his or her rational capabilities

- work that supports the moral development of employees

- work which is not governed by paternalistic approaches or measures.

Where compliance with these conditions exists the organisation can be viewed as a so-called moral organisation.

The meaning of work (MOW) project team: The MOW International Project team gathered data in 8 countries (Harpaz 1990) eventually contributing to an understanding of the construct meaning of work (Morse \& Weiss 1955; Sverko 1999; Magdoff 1982; Ross, Schwartz \& Surkiss 1999) through the creation of a heuristic model within which sets of variables and relationships between variables were considered to be of primary importance (Basini \& Buckley 1996-1997). This led to a conceptualisation of the meaning of work on multiple dimensions, such as:

- work centrality in people's lives

- work role identification

- valued working outcomes

- work goals

- societal norms about working.

Findings indicate that people with a higher work centrality inclination are more involved in their work, resulting in a tendency to work longer hours (MOW International Research Team 1987; Hirschfeld \& Feild 2000; Snir \& Harpaz 2002), whilst acting at higher levels of performance, and demonstrating higher levels of job involvement and 
commitment to the organisation (Hirschfeld \& Feild 2000; Diefendorff et al. 2002; see also Sharabi \& Harpaz (2007:96). ${ }^{19}$

Individual values and work: The value category pertaining to meaningful work can be described according to four main dimensions, each encompassing sub-dimensions. These include the following:

- Transcendence, constituted by:

- universalism

- benevolence.

- Conservation which is construed by:

- conformity

- tradition

- security.

- Self enhancement encompassing:

- power

- achievement

- hedonism

- Openness to change which is constituted by:

- stimulation

- self direction.

The necessity to establish a link between universal values and work values has been examined by Ross et al. (1999) who state:

Like basic values, work values are beliefs pertaining to desirable end-states (e.g. high pay) or behaviour (e.g. working with people). Work goals would naturally be ordered according to their impact on outcomes or end-states. Work values are more specific because of the fact that they are defined within context. Despite a plethora of different labels researchers appear to identify the same two or three types of work values (1) intrinsic or self-actualisation values (2) extrinsic or security or material values (3) social or relational values and (4) prestige work values. ${ }^{20}$ (pp. 54-55)

Work ethic ${ }^{21}$ : Suffice it to indicate the factors that identify and describe the Protestant Ethic (PE) for the purpose of a broad overview. These factors have been noted by Maximilian Weber ([1905] 2002) in his essay: 'The Protestant Ethic and the Sprit of Capitalism'. The characteristic elements of PE include:

- Protestant Work Ethic (PWE) believers differentiate between extrinsic and intrinsic needs and values.

- The assessment of the PWE among respondents in different studies furthermore identify the following core values:

- Hard work as such is viewed as a moral value. This is closely linked with what Weber referred to as the 'Doctrine of Calling' and the 'Doctrine of Predestination'. The external signs of being one of the elect is in the measure of success achieved in work.

- Work represents the fulfilment of earthly duties and is viewed as a calling.

- PE accentuates individualism as a value that is imbedded in Protestant theology, although this might be balanced with the collective calling of the church

19.See also Steenkamp (2012:188-193).

20.See Steenkamp (2012:194-200).

21.The second article will focus exclusively on the Protestant ethic and will thus not be discussed here. in the world (this seems to be one of the dialectical moments in Protestant theology).

- Protestantism underlines personal responsibility in the intra-personal as well as the interpersonal (social) domains and work provides the framework for individual choice and work execution (i.e. work behaviour as an individual).

- Rational and practical asceticism without falling into the trap of Catholicism's separation from worldly events. As used by Weber, it refers to a practical devotional lifestyle that is open to the world and its realities.

Workplace spirituality: Workplace spirituality as factor in the meaningful work model is construed by the following elements:

- a sense of meaning at work

- workplace community

- aligned with workplace values

- intrinsic job satisfaction and involvement

- organisation commitment

- organisation based self-esteem.

The above factors and their respective elements represent the descriptors that correspond with an integrated perspective of the human as seeking a balance and meaning in work-life.

Meaningfulness at work as a (second) macro constitutive dimension of the construct: A meaningful workplace ${ }^{22}$

The following summarised discussion represents the factors and elements that constitute the second macro constitutive dimension of the construct under discussion and focuses on organisational related factors that induce the experience of meaningfulness in or at the workspace. This dimension is primarily concerned with those factors and their constituent elements that create a meaningful psychological space.

The workplace as dynamic space: To make decisions we rely on our spatial situatedness in and understanding of the world. This is referred to as the cognitive mapping process of the individual. This process and ability are associated with the encoding and retrieving of information (Kitchin \& Blades 2002). This is also true of the workplace as 'space'. The workplace as dynamic space is underpinned by the following elements:

- the workplace represents psychological space

- the workplace represents individual space

- the workplace also represents perceptual space.

The workplace as work and job characteristics space: Job characteristics and the psychological conditions for meaningfulness define the workplace as characteristics space. The following elements underpin the psychological conditions for meaningfulness:

- skill variety

- task identity

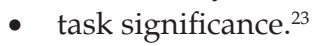

22.See Figure 1 for the structure behind the reasoning. The meaningful workplace is construed by means of two separate, yet interdependent macro constitutive dimensions that collude on a conceptual level, based on which the meaningful workplace is described and defined.

23.This is based on the Hackman-Oldham model (1980) and can be followed in Steenkamp (2012). 
The critical psychological states associated with these characteristics are referred to as 'experienced meaningfulness at work, experienced responsibility for work outcomes, and knowledge of actual work results' (Hackman \& Oldham 1980:n.p.).

The workplace as achievement space: Described as achievement space the tasks associated with the work role of the individual, requires the expenditure of energy as the facilitating elements of work role fulfilment in order to reach the state of productiveness by employees.

The workplace as problem solving space: Problem solving requires the application of complex thought patterns as required for a specific job function or sequence of workrelated roles. It requires the identification of a problem, moving into the problem zone, searching for solutions, choosing the best solution and applying this within the context of the job function.

The workplace as transformation space: Work role activities, employees who perform these activities and the organisation as such are constantly subject to changing practices that at times only require adjustments in work role and behaviour, whilst at other times require radically new work role behaviours. This implies a changed knowledge and skills base as well as altered attitudes and cultural changes which drastically and radically impact on relationships in the workplace. Some transformations can be so disruptive as to tear the fabric of the organisation apart.

The workplace as commitment space: From an organisational or managerial perspective, commitment matters especially in view of the many rapid changes that organisations have to successfully negotiate for survival. Commitment is an attitude of non-compromise applied to different workplace dimensions and represents different dimensions such as:

- commitment towards wards the personal work role

- commitment to the organisation, supervisor, manager, peers, group members, et cetera, represents other commitment dimensions or organisational entities.

The workplace as culture space: A variety of dimensions underpin the organisation as culture space. These include but are not necessarily limited to:

- management procedure trends

- leadership style

- the creation of workplace community and the supportive characteristics of such a community

- acknowledgement, acceptance and diversity dimensions including the psychodynamic factor of diversity

- organisational identity and identification of the employee with the organisation thereby also creating an own organisational identity

- organisational ideology.

The factors that have been listed above represent those factors that are controlled for or managed within the workplace, that facilitate the experience of meaning in working whilst performing work role activities.

\section{The meaningful workplace defined}

What is a meaningful workplace? (The following discussion is based on Steenkamp 2012). The meaningful workplace is an environment:

- Filled with human behavioural dynamic (interactivity, rational as well as emotionality laden) and many other stimuli (tangible as well as intangible) wherein people do formal work that contributes towards a meaningful life condition.

- That refers to a subjective reality filled with meaningful experiences that are enacted through behaviour patterns stemming from (1) an intrapersonal perspective or approach and (2) resulting in interpersonal and interactive cycles of activity that engender meaningfulness.

- It is furthermore an environment:

- where alignment regarding the purpose and future ideal of the organisation is achieved through an understanding of and respect for individual organisation members

- where organisation members are valued as humans and not only for the contributions they make towards achieving common goals

- where there is no limit to the growth and development of people

- where people reach the experience of a common social reality and belonging

- where the individual becomes an integrated role player in and of work structure planning

- where all of factors are orchestrated to create and sustain commitment and productive work-role behaviour.

- Wherein which an objective and achievable reality based is created, based on practices that foster the psychological conditions of meaningfulness.

- That enables the employee to apply his or her capabilities to transcend the self and achieve self-actualisation through a sense of belonging and achievement. This implies being able to commit, transform, expend energy, create a personal space in which to solve problems, where the culture allows self-expression without punitive measures; an environment where the conditions for psychological meaningfulness are mediated by skills variety, task significance, and task identity.

- Or psychological space in which the individual as unique being is totally involved, and where, in ideal circumstances the organisation accommodates and supports the whole person in respect of the need for work-life balance. This requires the alignment between the individual's values, life purpose, ethical orientation towards life and work, purpose, et cetera and mission of the organisation. This requires and implies an integrated wholeness and healthiness of the individual and the organisation.

- Where the 'community' dimension is purposefully pursued as an important dimension of meaningfulness. Being part of the community, the employee accepts ownership and experiences pride to be associated with the organisation. 


\section{The meaningful workplace: A perspective on values with specific reference to the Protestant Ethic}

A complex of dimensions which are clustered under the common denominator 'values' as part of the meaning of work model, can be identified as contributing towards the construct: 'A Meaningful Workplace'. The 'values complex' consists of universal individual values related to work, specific work-type values, and the values emanating from or as described by the 'Protestant Ethic' as well as spiritual values. This cluster can be referred to as 'values and work ethic'. It is reasoned that this value cluster contributes to (1) the creation of meaningful work experiences, and by inference, (2) to the creation of a meaningful workplace. This perspective will be addressed in a following article titled: 'Protestant Ethic: Contributing towards a meaningful work experience and a meaningful workplace.'

\section{Conclusion}

In conclusion, although the discussion did not deep-dive into the detail of the concepts that are presented above, there is sufficient material to construe the construct: 'meaningful workplace' through the identification above. The meaningful workplace is an emerging construct in literature and does not only enhance the field of management theory, but also the field of organisational behaviour. From this point of view it provides a parallel (or possibly even an alternative) way of understanding the behaviour of humans in organisations.

In conclusion and in summarised form it can be stated that the 'meaningful workplace' is (1) an environment (which is defined and characterised as meaningfulness at work) where people (2) perform meaningful work (which is described and defined as the meaning of work), and (3) where employees experience meaningfulness as all the requirements for psychological safety, psychological availability and community are complied with. It is therefore hypothesised (as is common in the arena of qualitative research programmes) that the integration of those factors and dimensions that have been identified within the two macro constitutive dimensions will contribute towards the establishment of a meaningful workplace, thus resolving the issue of alienation and the loss of meaning.

In a following article the contributory function of values and imbedded therein PE as construed by Max Weber will be discussed as contributory towards the experience of meaningfulness in the workplace, while performing work.

\section{Acknowledgements}

The authors declare that they have no financial or personal relationship(s) which may have inappropriately influenced them in writing this article.

\section{Authors' contributions}

P.L.S. (University of Pretoria) researched the construct 'A Meaningful Workplace' under the supervision of J.S.B.
(University of Pretoria; Professor in Human Resource Management). The resulting article was written by P.L.S. and submitted for approval to J.S.B., who approved the article with recommendations for content changes, which were effected.

\section{References}

Ashforth, B.E., 1989, 'Social Identity Theory and the Organization', Academy of Management Review 14(1), 20-39.

Basini, S. \& Buckley, F., 1996-1997, 'Employee needs and expectations in the Irish voluntary sector', DCUBS Research papers 1996-1997, Monthly Labour review.

Bateson, G., 1972, Steps to an ecology of mind, University of Chicago Press, Chicago, IL.

Boje, D., Gephart, R.P. \& Thatchenkery, T.J. 1996, 'Post modern management and the coming crises of organizational management', in D. Boje, R.P. Gephart \& T.J. Thatchenkery (eds.), Postmodern management and organization theory, $\mathrm{pp}$. 1-12, SAGE Publications, Thousand Oaks, CA.

Bowie, N.E., 1998, 'A Kantian Theory of Meaningful Work', Journal of Business Ethics 17(9/10), 1083-1092. http://dx.doi.org/10.1023/A:1006023500585

Cameron, K.S., Dutton, J.E. \& Quinn, R.E. (eds.), 2003, Positive organizational scholarship, Berrett-Koehler, San Francisco, CA.

Casey, C., 2002, Critical analysis of organizations: Theory, practice and revitalization, SAGE Publications, London.

Chalofsky, N., 2003, 'An Emerging Construct for Meaningful Work', Human Resource Development International 6(1), 69-83. http://dx.doi.org/10.1080/ 1367886022000016785

Chalofsky, N., 2010, Meaningful workplaces: Reframing where and how we work, Jossey-Bass, San Francisco, CA.

Chalofsky, N.E. \& Griffin, M.J., 2005, 'It Takes a Community', Training and Development 59(1), 42-47. http://dx.doi.org/784345001

Cilliers, F. \& Koortzen, P., 2000, 'The psychodynamic view on organizational behavior', in Society for Industrial and Organizational Psychology, Inc., viewed 16 January 2008, from http://www.siop.org/tip/backissues/TipOct00/08Cilliers.htm

Collinson, D., 1992, Managing the shopfloor: Subjectivity, masculinity, and workplace culture, Walter de Gruyter, New York, NY. http://dx.doi.org/10.1515/9783110879162, PMCid:206236

Cummings, T.G \& Manring, S.L., 1977, 'The Relationship between Worker Alienation and Work-Related Behavior', Journal of Vocational Behavior 10(2), 167-179. http://dx.doi.org/10.1016/0001-8791(77)90053-7

Daft, R.L. \& Steers R.M. 1986, Organizations: A micro/macro approach, Scott/ForesmanAddison Wesley Publishing Company, Boston, MA.

Daft, R.L. \& Steers R.M., 1990, Organizations: A micro/macro approach, Scott Foresman, Glenview, IL.

Denzin, N.K. \& Lincoln, Y.S. 1994, 'Introduction - Entering the field of qualitative research', in N.K. Denzin \& Y.S. Lincoln (eds.), Handbook of Qualitative Research, pp. 1-18, SAGE Publications, London.

Denzin, N.K \& Lincoln, Y.S., (2000), The discipline of qualitative research: Handbook of qualitative research, 2 nd edn., SAGE Publications, London

Diamond, M \& Allcorn, S., 2003, 'The Cornerstone of Psychoanalytic Organizational Analysis: Psychological Reality, Transference and Counter Transference in the Workplace', Human Relations 56(4), 491-514. http://dx.doi.org/10.1177/ 0018726703056004005

Diefendorff, J.M., Brown, D.J, Kamin, A.M. \& Lord, R.G., 2002, 'Examining the Roles of Job Involvement and Work Centrality in Predicting Organizational Citizenship Behaviors and Job Performance', Journal of Organizational Behavior 23(1), 93-108. http://dx.doi.org/10.1002/job.123

Engholm, P., 2001, 'The controversy between modernist and postmodernist views of management science: Is a synergy possible?', in The Engelholm Tribune, viewed 04 February 2013, from http://www.x-konsult.se/academia/Essaymgc1.htm

Frankl, V., 2004, Man's search for meaning, Random House, London.

Gergen, M.M. \& Gergen K.Z., 2000, 'Qualitative enquiry: Tensions and transformations', in N.K. Denzin \& Y.S. Lincoln (eds.), Handbook of qualitative research, pp. x-xx, SAGE Publications, London.

Gergen, K.J. \& Thatchenkery, T.J., 2004, 'Organization Science as Social Construction Postmodern Potentials', Journal of Applied Behavioral Science 40(2), 228-249. http://dx.doi.org/10.1177/0021886304263860

Gephardt, R.P. Jr, 1996, 'Postmodernism and the Future History of Management: Comments on History as Science', History of Management Science 2(3), 90-96. http://dx.doi.org/10.1108/13552529610127722

Guba, E.G. \& Lincoln, Y.S., 1994, 'Competing paradigms in qualitative research', in N.K. Denzin \& Y.S. Lincoln (eds.), Handbook of Qualitative Research, pp. 105-117, SAGE Publications, London.

Hackman, J.R. \& Oldham, G.R., 1980, Work redesign, Addison-Wesley Publishing Company, Inc., Boston, MA. (Addison Wesley Series). PMCid:1282848

Harpaz, I., 1990, The meaning of work in Israel: Its nature and consequences, Praeger, New York, NY.

Hawking, S., 1988, A brief history of time, Bantam Books, New York, NY. PMid:9958757

Herzberg, F., Mausner, B. \& Snyderman, B. 1969, 'Work and motivation', in H.M.F. Rush (ed.), Behavioral science: Concepts and management application: Studies in personnel policy, pp. 20-39, National Industrial Conference Board, New York, NY. 
Hirschfeld, R.R. \& Feild, H.S., 2000, 'Work Centrality and Work Alienation: Distinct Aspects of a General Commitment to Work. Journal of Organizational Behavior 21(7), 789-800. http://dx.doi.org/10.1002/1099-1379(200011)21:7<789::AID21(7), 789-800. http:
JOB59>3.0.CO;2-W

Janesick, V.J., 1994, 'The dance of qualitative research design: Metaphor, methodolatry and meaning', in N.K. Denzin \& Y.S. Lincoln (eds.), Handbook of qualitative research, pp. 209-229, SAGE Publications, London.

Jaggi, B., 1988, 'A comparative analysis of worker participation in the United States and Europe', in G. Dlugos, W. Dorow, K. Weiermair \& F.C. Danesy (eds.), Management under differing labour market and employment systems, pp. 430-454, Walter de Gruyter, Berlin.

Kelly, G.A., 1963, A theory of personality: The psychology of personal constructs, Norton, New York, NY.

Kitchin, R. \& Blades, M., 2002, The cognition of geographic space, J.B. Taurus \& Company, Ltd. London.

Kotzé, M., 1995, 'Die identifisering van topbestuursparadigmas: 'n Kwalitatiewe analise', doktorale proefskrif, Departement Opvoedkunde, Universiteit van Pretoria. PMCid:1050434

Laverty, S.M., 2003, 'Hermeneutic Phenomenology and Phenomenology: A Comparison of Historical and Methodological Considerations', International Journal of Qualitative Methods 2(September), 1-29.

Levering, R., 2000, A great place to work, Great Place to Work Institute, San Francisco, CA. PMid:10797446

Magdoff, H., 2006, 'The Meaning of Work: A Marxist Perspective', Monthly Review 58(5), October.

May, D., Gilson, R. \& Harter, L., 2004, 'The Psychological Conditions of Meaningfulness, Safety and Availability and the Engagement of the Human Spirit at Work', Journa of Occupational and Organizational Psychology 77(1), 11-27. http://dx.doi.org/ 10.1348/096317904322915892

McFillen, J.M., 1985, 'The Organizing and Managing of Organizational Behavior: A Review of First Edition Organizational Behavior Texts', The Academy of Management Review 10(2), 355-366.

Miller, J.G., 1976, Living systems, McGraw-Hill, New York, NY.

Miller, M.D., 1985, Principles and a philosophy for vocational education, National Center for Research in Vocational Education, Ohio State University, Columbus, $\mathrm{OH}$.

Morse, N.C. \& Weiss, R.S., 1955, 'The Function and Meaning of Work and the Job', American Sociological Review 20(2), 191-198. http://dx.doi.org/10.2307/2088325

Mostert, K., 2004, 'Research Methodology', Bskp361: Study Guide, Faculty of Economic and Management Sciences, North-West University (Potchefstroom Campus), viewed 09 February 2012, from http://ework-win.puk.ac.za/sgo/docs/SkrywerFinaal/ 09 February 2012, from http://ewo

MOW International Research team, 1987, The meaning of working, Academic Press, London.

Nelson, D. \& Quick, J.C., 2000, Organizational Behaviour: Foundations realities and challenges, South-Western College Publishing, Cincinnati, $\mathrm{OH}$.

Rhodes, C., 2003, 'From the Modern to the Postmodern (and Back Again)' Review of Work, postmodernism and organization: A critical introduction by P. Hancock \& M Tyler, Ephemera 3(2), 156-161.
Robbins, S.P., 1998, Organizational behavior: Concepts, controversies, applications, Prentice-Hall International, Englewood Cliffs, NJ.

Ross, M. Schwartz, S.H. \& Surkiss, S., 1999, 'Basic individual Values, Work Values and the Meaning of Work', Applied Psychology: An International Review 48(1), 49-71. http://dx.doi.org/10.1111/j.1464-0597.1999.tb00048.x

Safranski, R., 1998, Martin Heidegger: Between good and evil, Harvard University Press, Cambridge, MA. PMid:9788745

Schwandt, T.A., 2000, 'Three epistemological stances for qualitative inquiry', in K. Denzin $\&$ Y. Lincoln (eds.), Handbook of qualitative research, 2nd edn., pp. 189-213, SAGE Publications, London.

Sharabi, M. \& Harpaz, I., 2007, 'Changes in Work Centrality and Other Life Areas in Israel: A Longitudinal Study', Journal of Human Values 13, 95-106. http://dx.doi. org/10.1177/097168580701300203

Shepard, J.M., 1971, Automation and alienation: A study of office and factory workers, MIT Press, Cambridge, MA.

Smith, D.W., 2008, s.v. 'Phenomenology', in E.N. Zalta (ed.), The Stanford Encyclopaedia of Philosophy, viewed no date, from http://plato.stanford.edu/archives/fall2011/ entries/phenomenology

Snir, R. \& Harpaz, I., 2002, 'To Work or Not to Work: Nonfinancial Employment Commitment and the Social Desirability Bias', The Journal of Social Psychology 142(5), 635-644. http://dx.doi.org/10.1080/00224540209603923

Steenkamp, P.L., 2012, 'A meaningful workplace: From theory development to applicability', PhD thesis, Department of Economic and Management Science, University of Pretoria.

Stewart, V. \& Stewart, A., 1990, Business applications of repertory grid, Assessment Centre Study group, National Book Printers, Goodwood.

Sverko, B., 1999, 'The Work Importance Study: Recent Changes of Values in Croatia', Applied Psychology: An International Review 48(1), 89-102.

Terez, T., 2000, 22 Keys to creating a meaningful workplace, Adams Media Corporation, London.

Trochim, W.M., 2006, 'Deduction \& induction: Deductive and inductive thinking', in Web Centre for Social Research Methods, viewed 10 August 2008, from http:// www.socialresearchmethods.net/kb/dedind.php

Vecchio, R., 1980, 'The Function and Meaning of Work and the Job: The work of Morse and Weiss revisited', The Academy of Management Journal 23(2), 361-367. http://dx.doi.org/10.2307/255439

Weber, M., [1905] 2002, The Protestant ethic and the spirit of capitalism, transl. S. Kalberg, Roxbury Publishing Company, Chicago, IL. http://dx.doi.org/10.1522/cla. wem.sec

Weisbord, M.R., 1987, Productive workplaces: Organizing and managing for dignity, meaning and community, Jossey-Bass, San Francisco, CA.

Wiese, B.S. \& Freund, A.M., 2005, 'Goal Progress Makes One Happy, or Does It? Longitudinal Findings from the Work Domain', Journal of Occupational and Organizational Psychology 78, 287-304. http://dx.doi.org/10.1348/096317905X26714

Yankelovich, D., 1981, New rules: Searching for self-fulfilment in a world turned upside down, Random House, New York, NY.

Yankelovich, D. \& Immerwahr, J., 1984, 'Putting the Work Ethic to Work', Society 21(2), 58-76. http://dx.doi.org/10.1007/BF02695027 